\title{
HDL-associated estradiol stimulates endothelial NO synthase and vasodilation in an SR-BI-dependent manner
}

\author{
Ming Gong, ${ }^{1}$ Melinda Wilson, ${ }^{1}$ Thomas Kelly, ${ }^{2}$ Wen Su, ${ }^{1}$ James Dressman, ${ }^{1}$ Jeanie Kincer, ${ }^{1}$ \\ Sergey V. Matveev, ${ }^{1}$ Ling Guo, ${ }^{1}$ Theresa Guerin, ${ }^{1}$ Xiang-An Li, ${ }^{1}$ Weifei Zhu, ${ }^{3}$ \\ Annette Uittenbogaard, ${ }^{1}$ and Eric J. Smart ${ }^{1}$ \\ ${ }^{1}$ Department of Pediatrics, \\ ${ }^{2}$ Department of Behavioral Sciences, and \\ ${ }^{3}$ Department of Nutritional Sciences, University of Kentucky Medical School, Lexington, Kentucky, USA
}

\begin{abstract}
Cardiovascular diseases remain the leading cause of death in the United States. Two factors associated with a decreased risk of developing cardiovascular disease are elevated HDL levels and sex specifically, a decreased risk is found in premenopausal women. HDL and estrogen stimulate eNOS and the production of nitric oxide, which has numerous protective effects in the vascular system including vasodilation, antiadhesion, and anti-inflammatory effects. We tested the hypothesis that HDL binds to its receptor, scavenger receptor class B type I (SR-BI), and delivers estrogen to eNOS, thereby stimulating the enzyme. HDL isolated from women stimulated eNOS, whereas HDL isolated from men had minimal activity. Studies with ovariectomized and ovariectomized/estrogen replacement mouse models demonstrated that HDL-associated estradiol stimulation of eNOS is SR-BI dependent. Furthermore, female HDL, but not male HDL, promoted the relaxation of muscle strips isolated from C57BL/6 mice but not SR-BI null mice. Finally, HDL isolated from premenopausal women or postmenopausal women receiving estradiol replacement therapy stimulated eNOS, whereas HDL isolated from postmenopausal women did not stimulate eNOS. We conclude that HDL-associated estrodial is capable of the stimulating eNOS. These studies establish a new paradigm for examining the cardiovascular effects of HDL and estrogen.
\end{abstract}

J. Clin. Invest. 111:1579-1587 (2003). doi:10.1172/JCI200316777.

\section{Introduction}

The development of cardiovascular diseases is a multifactorial process that is influenced by both genetic and environmental factors. Two factors that modulate the development of cardiovascular diseases are HDL and estradiol (1-3). Both HDL and estradiol can promote the stimulation of eNOS and the subsequent generation of nitric oxide (4-8). Nitric oxide is a critical player in the physiology and pathophysiology of the vascular system and is thought to be involved in preventing the oxidation of lipoproteins (9), preventing the adhesion of monocytes to the endothelium $(10,11)$, downregulating inflammatory mediators $(10,11)$, and promoting vessel vasodilation $(12,13)$. Our current studies have focused on how HDL and estradiol interact to stimulate endothelial nitric oxide synthase and the generation of nitric oxide.

Received for publication Angust 28, 2002, and accepted in revised form March 25, 2003.

Address correspondence to: Eric J. Smart, University of Kentucky, Department of Pediatrics, 423 Sanders-Brown, 800 Limestone Street, Lexington, Kentucky 40536-0230, USA. Phone: (859) 323-6412; Fax: (859) 257-2120;

E-mail: ejsmart@uky.edu.

Conflict of interest: The authors have declared that no conflict of interest exists.

Nonstandard abbreviations used: scavenger receptor class B type I (SR-BI); human microvascular endothelial (HME).
Numerous studies have demonstrated that HDL is cardioprotective and lowers the risk of developing cardiovascular disease (14-16). A large part of the protective effects of HDL is thought to be due to the role HDL plays in reverse cholesterol transport $(17,18)$. HDL can lower total plasma cholesterol levels by transporting cholesterol from the peripheral tissues to the liver. HDL binds to a receptor called scavenger receptor class B type I (SR-BI) in the liver and subsequently delivers the sterol to hepatocytes for excretion as bile or recycling into other lipoprotein particles $(19,20)$. Our previous studies demonstrated that SR-BI was also expressed in endothelial cells and localized to plasma membrane caveolae $(5,21)$. This led to the concept that HDL and SR-BI also may affect the vascular system independently of their role in decreasing plasma cholesterol. In a series of studies, we demonstrated that HDL, in a SR-BI dependent manner, could protect caveolae from the loss of cholesterol (21) and that HDL can promote the stimulation of caveola-localized eNOS by a mechanism involving ceramide (5). Independent work by Yuhanna et al. (4) demonstrated that HDL could promote the activation of eNOS and vessel dilation in an SR-BI-dependent manner.

Premenopausal women have a lower risk of developing cardiovascular disease than similarly aged men (22-24). The mechanism(s) that afford women protection from cardiovascular disease are not understood, although a considerable amount of research has 
focused on the role of estradiol in mediating some of the protection. Even though the utility of estradiol replacement therapy in treating cardiovascular disease is controversial, many mechanistic studies have demonstrated an important role for estradiol in the normal physiology of the vascular system $(2,25,26)$. Relevant to our current study, estradiol stimulates eNOS and increases the production of nitric oxide independently of nuclear events $(7,27,28)$. Chambliss et al. (7) demonstrated that estrogen receptors were localized to plasma membrane caveolae and that the addition of exogenous estradiol could stimulate eNOS. In addition, Haynes et al. (29) demonstrated that estrogen activates akt kinase, which subsequently phosphorylates and activates eNOS. The difficulties with previous studies arise in demonstrating specificity and physiological relevance, because the effects of estradiol on eNOS activity are usually determined by adding pharmacological doses of estradiol to cells in culture, using BSA as a carrier. The physiological carrier in the plasma that is responsible for the delivery of estradiol to eNOS has not been elucidated.

SR-BI and eNOS are both localized to caveolae in endothelial cells $(5,21)$, and SR-BI is known to facilitate the uptake of sterols into cells $(19,20)$. Therefore, we hypothesized that estradiol associated with plasma HDL is targeted to eNOS by the interaction of HDL with SR-BI in caveolae. The data demonstrate that estradiol associated with HDL stimulates eNOS and vessel relaxation.

\section{Methods}

Materials. M199, basal medium Eagle vitamin mix, fetal bovine serum, glutamine, trypsin-EDTA, and penicillin/streptomycin were from Life Technologies, Inc. (Grand Island, New York, USA). $\left[{ }^{3} \mathrm{H}\right]$ arginine (specific activity, $51 \mathrm{Ci} / \mathrm{mmol}$ ) was from New England Nuclear (Boston, Massachusetts, USA). Bradford reagent was purchased from BioRad (Hercules, California, USA). The mouse feed was obtained from Harlan Tekland (Madison, Wisconsin, USA). Dowex AG50WX-8 and Celite 545 were from Sigma-Aldrich (St. Louis, Missouri, USA). The Ultra-Sensitive Estradiol RIA kit was from Diagnostic System Laboratories Inc. (Webster, Texas, USA). Human serum was obtained from the American Red Cross (Lexington, Kentucky, USA). Quality Control Biochemicals (St. Louis, Missouri, USA) generated the custom-made SR-BI blocking antibody (5). $\left[{ }^{125} \mathrm{I}\right] \mathrm{Na}(1 \mathrm{mCi} / \mathrm{ml})$ and $\left[2,4,6,7-{ }^{3} \mathrm{H}\right]$ estradiol $(87$ $\mathrm{Ci} / \mathrm{mmol}$ ) were purchased from New England Nuclear. Cell culture. Human microvascular endothelial cells (CDC.EU/HMEC-1 from the National Center for Infectious Diseases) were cultured in M199 medium supplemented with $100 \mathrm{U} / \mathrm{ml}$ penicillin/streptomycin, $0.5 \%(\mathrm{v} / \mathrm{v})$ L-glutamine, BME vitamin $\operatorname{mix}(1 \mathrm{ml} / 100 \mathrm{ml}$ M199), BME amino acid mix (1 ml/100 ml M199), and $10 \%(\mathrm{v} / \mathrm{v})$ fetal bovine serum. On day $0,5,000$ cells were placed into 12 -well plates and used on day 3 at approximately $60 \%$ confluency.
Activation of NOS in intact cells. NOS activation was determined in intact cells as previously described (21, 30 ). Briefly, the cells were plated into 12 -well plates at 5,000 cells per well and grown to $60 \%$ confluency. The medium was replaced with serum-free medium for 16 hours and the cells then placed for 2 hours in phosphate-buffered saline at $37^{\circ} \mathrm{C}$. After the preincubation period, the PBS was removed from the wells and replaced with $400 \mu \mathrm{l}$ of PBS containing $0.75 \mu \mathrm{Ci} / \mathrm{ml}$ $\left[{ }^{3} \mathrm{H}\right] \mathrm{L}$-arginine. The cells were incubated at $37^{\circ} \mathrm{C}$ for 15 minutes with the indicated treatments. The NOS reaction was terminated by adding $500 \mu \mathrm{l}$ of ice-cold $1 \mathrm{~N}$ trichloroacetic acid (TCA) to each well. The cells were freeze-fractured twice in liquid nitrogen for 2 minutes with thawing at $37^{\circ} \mathrm{C}$ for 5 minutes and scraped with a rubber spatula. The contents of each well were transferred to ice-cold glass test tubes. Ether extraction was performed three times with water-saturated ether to remove the TCA. The samples were neutralized with $1.5 \mathrm{ml}$ of $25 \mathrm{mM}$ HEPES ( $\mathrm{pH} 8$ ) applied to Dowex AG50WX-8 (Tris form) columns and eluted with $1 \mathrm{ml}$ of $40 \mathrm{mM}$ HEPES buffer ( $\mathrm{pH} 5.5$ ) containing $2 \mathrm{mM}$ EDTA and $2 \mathrm{mM}$ EGTA. $\left[{ }^{3} \mathrm{H}\right] \mathrm{L}$-citrulline was collected in scintillation vials and quantified by liquid scintillation counting. In individual experiments performed in 12-well plates, 3 wells were used for each treatment group. Findings were confirmed in at least six independent experiments. NOS activation in the intact cells was inhibited by $1 \mathrm{mM}$ nitro-L-arginine methyl ester (over $99 \%$ of NOS activity inhibited). To ensure that the treatments did not affect the loading of the cells with $\left[{ }^{3} \mathrm{H}\right] \mathrm{L}$-arginine, the amount of $\left[{ }^{3} \mathrm{H}\right] \mathrm{L}$-arginine associated with the cells was determined. The cells contained 220,000 $\pm 9,184$ disintegrations per minute per well of $\left[{ }^{3} \mathrm{H}\right] \mathrm{L}$-arginine independently of the treatment. For the estrogen antagonist assays, $10 \mu \mathrm{M}$ of ICI 182,780 was added to the HDL and $\left[{ }^{3} \mathrm{H}\right] \mathrm{L}$-arginine mixture. The mixture was then incubated with cells for 15 minutes, the reaction was stopped with TCA, and the cells were processed to quantify the amount of $\left[{ }^{3} \mathrm{H}\right] \mathrm{L}$-citrulline generated. Lipoproteins. VLDL (density, less than $1.006 \mathrm{~g} / \mathrm{ml}$ ), LDL (density, 1.019-1.05 g/ml), and HDL (density, $1.063-1.21 \mathrm{~g} / \mathrm{ml}$ ) were isolated from human or mouse plasma by sequential density gradient ultracentrifugation as described (31). SDS-PAGE and Coomassie staining were used to assay the purity of each lipoprotein fraction. HDL, LDL, and BSA were loaded with estradiol by a method similar to that used to label HDL with cholesteryl ester (32). In brief, estradiol (1-50 mg) was dried onto $100 \mathrm{mg}$ of Celite 545 and then incubated with purified HDL, LDL, or BSA for 18 hours at $37^{\circ} \mathrm{C}$. At the end of the incubation, Celite was removed by centrifugation through $0.02 \mu \mathrm{m}$ filters. The HDL, LDL, and BSA were then reisolated by ultracentrifugation to ensure that unincorporated estradiol was removed. Control HDL, LDL, and BSA were treated identically, with the exception that estradiol was not added to the Celite. HDL was labeled with ${ }^{125} \mathrm{I}$ as described (33). 
Estradiol quantification. The amount of estradiol associated with HDL, LDL, or BSA was determined by first extracting lipids by solid-phase extraction using an Oasis HLB glass cartridge (Waters, Milford, Massachusetts, USA). The sample was diluted 1:1 (v/v) with glacial acetic acid and applied to the column. The column was washed with $40 \%$ methanol in water and the lipid eluted with $10 \%$ methyl butyl ether. The amount of estradiol in the eluent was quantified by radioimmunoassay using a commercially available kit (UltraSensitive Estradiol RIA) according to the manufacturer's instructions. Control experiments confirmed the linearity of the assay between the range of $4 \mathrm{pg} / 200 \mu \mathrm{l}$ and $150 \mathrm{pg} / 200 \mu \mathrm{l}$.

Hormone replacement. Eight-week-old mice (C57BL/6) were ovariectomized to eliminate endogenous ovarian steroids (34). Both female and male mice were then implanted subcutaneously with a Silastic capsule (inner/outer diameter, $0.062 \mathrm{in} / 0.125 \mathrm{in}$; volume, 0.035 $\mathrm{ml})$ containing $17-\beta$-estradiol $(180 \mu \mathrm{g} / \mathrm{ml})$ in sesame oil. The Silastic capsules consistently releases hormone over 10 days, producing stable plasma levels of $17-\beta$ estradiol (31 $\pm 13 \mathrm{pg} / \mathrm{ml})$ (34). Age- and sex-matched animals were used throughout the studies.

Arterial relaxation studies. The direct relaxation effect of HDL on arterial vessels was evaluated in mice spiral femoral artery strips $(150 \mu \mathrm{m}$ in width, $3 \mathrm{~mm}$ in length, and about $30-40 \mu \mathrm{m}$ in thickness). Femoral arteries were removed from 3-month-old male C57BL/6 or SR-BI null mice. Isometric tension was measured at $24^{\circ} \mathrm{C}$ with a force transducer as previously described (35). After equilibration and submaximal precontraction with 5-hydroxytryptamine (30 nM), relaxation to $1 \mu \mathrm{M}$ acetylcholine was tested to confirm the integrity of the endothelium. After washing, the strips were again contracted with 5-hydroxytryptamine, and the effects of HDL were assessed. At the completion of the experiment, the relaxation response to acetylcholine was confirmed. In experiments in which the endothelium was denuded, the integrity of the smooth muscle was confirmed by normal amplitude of contraction to endothelin and normal amplitude of relaxation to sodium nitroprusside.

\section{Figure 1}

$\mathrm{HDL}$ isolated from female subjects stimulates the production of nitric oxide. HDL, LDL, and VLDL were isolated from young, reproductively competent female humans (a) and mice (b) and age-matched male humans (a) and mice (b) (31). The freshly isolated lipoproteins (10 $\mu \mathrm{g} / \mathrm{ml}$ ) were incubated with human microvascular endothelial cells that had been prelabeled with $0.75 \mu \mathrm{Ci} / \mathrm{ml}$ of $\left[{ }^{3} \mathrm{H}\right]$ arginine for 15 minutes at $37^{\circ} \mathrm{C}(21)$. An additional set of cells was treated with 1 $\mu \mathrm{g} / \mathrm{ml}$ of ionomycin to determine the maximal eNOS stimulation. The cells were then washed, lysed, and extracted, and radiolabeled arginine was separated from radiolabeled citrulline using an ionexchange column. Each experiment included controls, using $1 \mathrm{mM}$ L-NNA to demonstrate that over $99 \%$ of the generated citrulline was due to eNOS activity (data not shown). In (c), a concentration curve of the effect of female HDL on eNOS activity is shown. The data are from six to eight independent experiments, with triplicate measurements in each experiment (mean $\pm \mathrm{SE}$ ).

\section{Results}

Female HDL but not male HDL stimulates eNOS. To determine if female and male HDL had a different capacity to stimulate eNOS, we isolated HDL, LDL, and VLDL from male and female human serum and from male and female mouse serum (31). We then used our established human microvascular endothelial (HME) cell system to assay the ability of the isolated lipoproteins to stimulate eNOS in live, intact cells $(5,21)$. HME cells were incubated with $0.75 \mu \mathrm{Ci} / \mathrm{ml}$ of $\left[{ }^{3} \mathrm{H}\right]$ arginine to label the intracellular arginine pool. Without removal of the radiolabel, the cells were then incubated with buffer only or $10 \mu \mathrm{g} / \mathrm{ml}$ of HDL, LDL, or VLDL for 15 minutes at $37^{\circ} \mathrm{C}$. In addition, another set of cells was treated with $1 \mu \mathrm{g} / \mathrm{ml}$ of ionomycin, a calcium ionophore, to determine maximal eNOS stimulation. The cells were then processed to quantify the amount of $\left[{ }^{3} \mathrm{H}\right]$ arginine converted to $\left[{ }^{3} \mathrm{H}\right]$ citrulline as a measure of enzymatic activity (Figure 1). Control experiments with $1 \mathrm{mM}$ L-NNA, an eNOS inhibitor, demonstrated that over $99 \%$ of the generated citrulline was due to eNOS

a

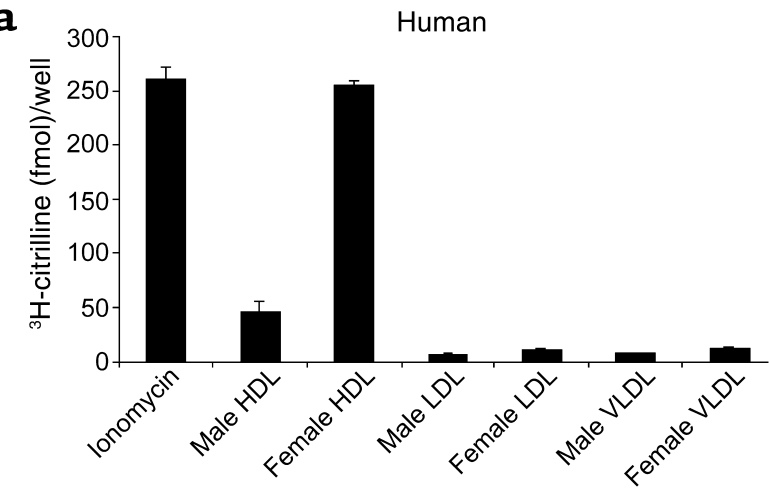

b

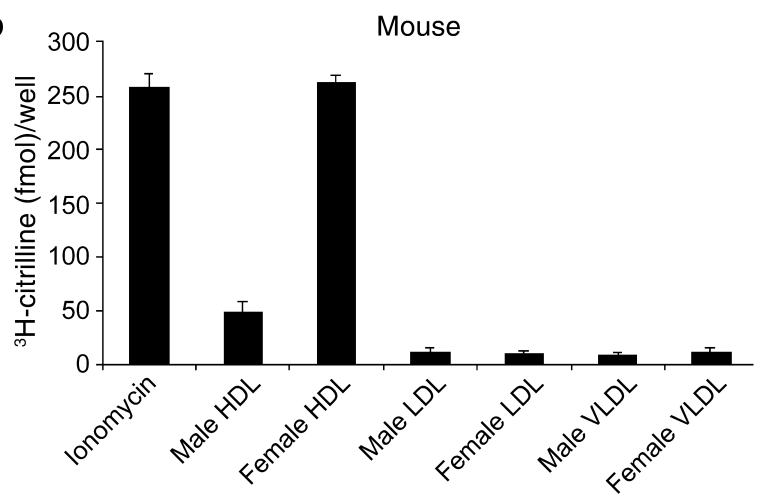

C

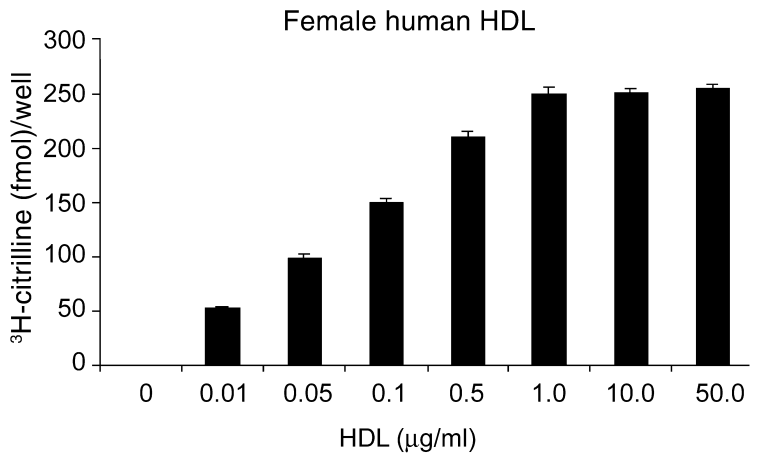




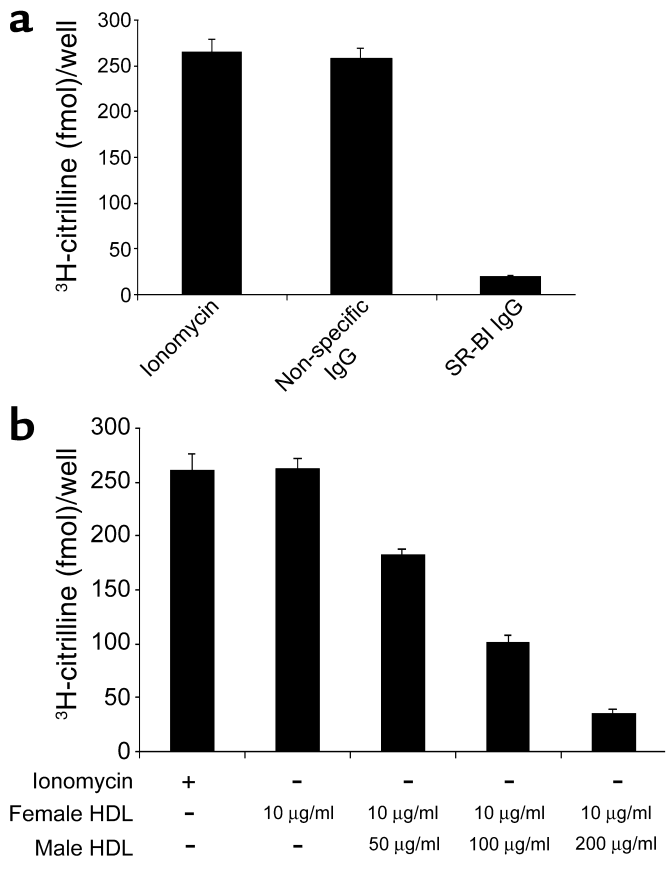

activity (data not shown). HDL $(10 \mu \mathrm{g} / \mathrm{ml})$ isolated from women (Figure 1a) and female mice (Figure 1b) stimulated eNOS to the same extent as ionomycin. Maximal stimulation of eNOS was achieved with 1 $\mu \mathrm{g} / \mathrm{ml}$ of HDL (Figure 1c). In contrast, HDL isolated from both men and male mice only weakly stimulated eNOS. The LDL and VLDL lipoprotein fractions isolated from both species and sexes did not stimulate eNOS. Even at high concentrations $(500 \mu \mathrm{g} / \mathrm{ml})$, male HDL or the LDL and VLDL fractions were unable to stimulate eNOS (data not shown).

The stimulation of eNOS by female $H D L$ requires $S R-B I$. To determine if the ability of female HDL to stimulate eNOS activity was dependent on SR-BI, we used SR-BI blocking antibodies and HME cells as we have done previously (21). HME cells were pretreated with buffer only, $50 \mu \mathrm{g} / \mathrm{ml}$ of blocking SR-BI IgG, or $50 \mu \mathrm{g} / \mathrm{ml}$ isotype-matched nonspecific IgG for 15 minutes at $37^{\circ} \mathrm{C}$. The cells were then incubated with $0.75 \mu \mathrm{Ci} / \mathrm{ml}$ of $\left[{ }^{3} \mathrm{H}\right]$ arginine and $10 \mu \mathrm{g} / \mathrm{ml}$ of female HDL for $15 \mathrm{~min}-$ utes at $37^{\circ} \mathrm{C}$. In addition, another set of cells was treated with $1 \mu \mathrm{g} / \mathrm{ml}$ of ionomycin to determine maximal eNOS stimulation. Figure 2a demonstrates that female HDL stimulated eNOS in cells pretreated with buffer or nonspecific IgG. In contrast, cells pretreated with

\section{Figure 2}

The ability of female HDL to stimulate eNOS requires binding to SR-BI. (a) Human microvascular endothelial cells were pretreated with buffer only, $50 \mu \mathrm{g} / \mathrm{ml}$ of blocking SR-BI IgG, or $50 \mu \mathrm{g} / \mathrm{ml}$ isotypematched nonspecific lgG for 15 minutes at $37^{\circ} \mathrm{C}$. The cells were then incubated with $0.75 \mu \mathrm{Ci} / \mathrm{ml}$ of $\left[{ }^{3} \mathrm{H}\right]$ arginine and $10 \mu \mathrm{g} / \mathrm{ml}$ of female $\mathrm{HDL}$ or $1 \mu \mathrm{g} / \mathrm{ml}$ of ionomycin for 15 minutes at $37^{\circ} \mathrm{C}$. The cells were processed to quantify the amount of citrulline generated. Each experiment included controls, using $1 \mathrm{mM} \mathrm{L-NNA}$ to demonstrate that over $99 \%$ of the generated citrulline was due to eNOS activity (data not shown). The data are from six independent experiments, with triplicate measurements in each experiment (mean $\pm \mathrm{SE}$ ). (b) Human microvascular endothelial cells were pretreated with $0.75 \mu \mathrm{Ci} / \mathrm{ml}$ of $\left[{ }^{3} \mathrm{H}\right]$ arginine and then incubated with $10 \mu \mathrm{g} / \mathrm{ml}$ of female $\mathrm{HDL}$ or increasing concentrations of male HDL for 15 minutes. The amount of citrulline generated was then quantified. Each experiment included controls, using $1 \mathrm{mM} \mathrm{L-NNA}$ to demonstrate that over $99 \%$ of the generated citrulline was due to eNOS activity (data not shown). The data are from six independent experiments, with triplicate measurements in each experiment (mean $\pm \mathrm{SE}$ ).

blocking SR-BI IgG did not increase eNOS activity in response to the addition of female HDL. To further ensure that the stimulation of eNOS required the association of female HDL with SR-BI, we used male HDL in a standard competition experiment. HME cells were incubated with $0.75 \mu \mathrm{Ci} / \mathrm{ml}$ of $\left[{ }^{3} \mathrm{H}\right]$ arginine, $10 \mu \mathrm{g} / \mathrm{ml}$ of female HDL, and increasing amounts of male HDL. Figure $2 \mathrm{~b}$ demonstrates that excess male HDL was able to compete for the ability of female HDL to stimulate eNOS activity. Male and female HDL did not affect ionomycin-induced eNOS activity (data not shown).

$H D L$-associated estradiol is responsible for eNOS stimulation. We hypothesized that estradiol associated with female HDL may be responsible for the stimulation of eNOS. To test this possibility, we quantified (34) the amount of estradiol associated with HDL isolated from men and women. Table 1 demonstrates that HDL isolated from women or female mice contained estradiol, whereas HDL isolated from men or male mice did not contain detectable amounts of estradiol. To determine if HDL-associated estradiol was responsible for the ability of female HDL to stimulate eNOS, we isolated HDL from C57BL/ 6 female mice that were intact, had their ovaries removed, or had their ovaries removed and a 17- $\beta$-estradiol pellet implanted to deliver physiological levels of estradiol (34). Intact animals had plasma estradiol levels of $29 \pm 12 \mathrm{pg} / \mathrm{ml}$, ovariectomized animals had plasma estradiol levels of less than $5 \mathrm{pg} / \mathrm{ml}$ (the detection limit is approximately $5 \mathrm{pg} / \mathrm{ml}$ ), and

Table 1

The quantification of estradiol

\begin{tabular}{lcccccccccc}
\hline & $\begin{array}{c}\text { Human } \\
\text { female HDL }\end{array}$ & $\begin{array}{c}\text { Human } \\
\text { male HDL }\end{array}$ & $\begin{array}{c}\text { Mouse } \\
\text { female HDL }\end{array}$ & $\begin{array}{c}\text { Mouse } \\
\text { male HDL }\end{array}$ & OVX & $\begin{array}{c}\text { OVX } \\
+ \text { E2 }\end{array}$ & $\begin{array}{c}\text { Male } \\
+ \text { E2 }\end{array}$ & $\begin{array}{r}\text { Male HDL } \\
+ \text { E2 }\end{array}$ & $\begin{array}{c}\text { LDL } \\
+ \text { E2 }\end{array}$ & $\begin{array}{c}\text { BSA } \\
+ \text { E2 }\end{array}$ \\
Estradiol/HDL & $0.024 \pm$ & ND & $0.015 \pm$ & ND & ND & $0.019 \pm$ & $0.012 \pm$ & $0.020 \pm$ & $0.018 \pm$ & $0.021 \pm$ \\
$(\mathrm{pg} / \mathrm{mg})$ & 0.004 & & 0.002 & & & 0.003 & 0.004 & 0.004 & 0.003 & 0.005
\end{tabular}

Estradiol was quantified as described in the Methods. Each value represents four independent experiments, with triplicate measurements in each experiment $($ mean \pm SE). ND, not detectable. 
ovariectomized animals containing an estradiol pellet had plasma estradiol levels of $31 \pm 13 \mathrm{pg} / \mathrm{ml}$. Importantly, estradiol could not be detected in HDL isolated from ovariectomized animals, whereas HDL isolated from ovariectomized animals receiving estradiol had levels similar to those of intact animals (Table 1). Determination of the ability of these HDLs to stimulate eNOS in HME cells was performed as described above. HDL isolated from intact mice stimulated eNOS to the same extent as the ionomycin control (Figure 3a). In contrast, HDL isolated from ovariectomized animals did not stimulate eNOS. The restoration of plasma and HDL estradiol levels in ovariectomized animals with an estradiol pellet restored the ability of isolated HDL to stimulate eNOS.

The ovariectomy studies strongly suggested that the estradiol associated with HDL was responsible for the stimulation of eNOS. To further test this possibility, male mice were implanted with estradiol pellets to increase the plasma level of estradiol to that of female mice (35 \pm 9 for male mice versus $29 \pm 12 \mathrm{pg} / \mathrm{ml}$ for female mice). HDL isolated from these mice stimulated eNOS nearly as well as HDL isolated from intact female mice (Figure 3a). In addition, when HDL isolated from untreated male mice was enriched with estradiol in vitro, this HDL maximally stimulated eNOS (Figure 3a), further suggesting that estradiol is the HDL component responsible for the activation of eNOS. In contrast, LDL and BSA enriched with comparable amounts of estradiol did not stimulate eNOS, indicating that estradiol needed to be associated with HDL to stimulate eNOS (Figure 3a). For all of the in vitro studies, the HDL, LDL, or BSA was reisolated after enriching in estradiol, and the amount of estradiol associated was quantified (Table 1). The nonactive stereoisomer of $17-\beta$-estradiol, $17-\alpha$-estradiol, did not stimulate eNOS under any conditions tested (data not shown), further suggesting that activation was due to $17-\beta$-estradiol and not some other HDL component. To further ensure that estradiol was the component of HDL responsible for eNOS stimulation, the ability of these HDLs to stimulate eNOS in HME cells was determined in the presence of the pure estrogen receptor antagonist ICI 182,780 (10 $\mu \mathrm{M})(36)$. The estrogen receptor antagonist did not affect ionomycin-mediated eNOS stimulation but completely inhibited HDL-mediated stimulation of eNOS (Figure $3 b)$, further implicating estradiol.

The data suggest that HDL delivers estradiol to the cells in an SR-BI-dependent manner, which subsequently stimulates eNOS. To determine if HDL is capable of delivering estradiol to the cells, we labeled male HDL with ${ }^{125}$ (labels the protein) and $\left[{ }^{3} \mathrm{H}\right]$ estradiol. Various concentrations of this double-radiolabeled HDL were then incubated with human microvascular endothelial cells for 15 minutes and processed to determine the amount of ${ }^{125} \mathrm{I}$ and ${ }^{3} \mathrm{H}$ associated with the cells. Table 2 demonstrates that ${ }^{125} \mathrm{I}$-labeled HDL associated with the cells and that the association was linear with respect to the concentration of HDL. In contrast, the amount of $\left[{ }^{3} \mathrm{H}\right]$ estradiol associated with the cells increased rapidly and was not linear with respect to the concentration of HDL. Importantly, the SR-BI blocking antibody prevented the association of both ${ }^{125} \mathrm{I}$ and ${ }^{3} \mathrm{H}$ with the cells. These data are similar to those seen when measuring the selective uptake of cholesteryl ester from HDL particles - namely, the amount of radiolabeled sterol associated with cells is much greater than can be accounted for by the association of HDL particles with SR-BI on the cell surface (37). These data demonstrate that even at low concentrations of HDL, enough HDL can associate with SR-BI to deliver estradiol to the cells.
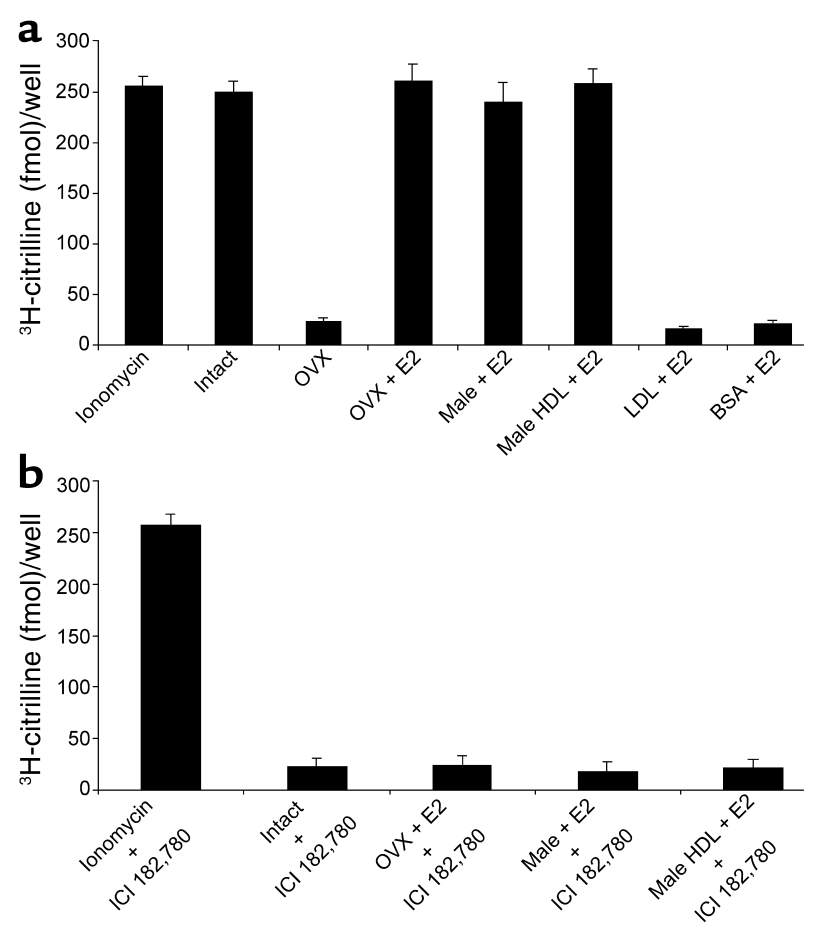

Figure 3

HDL-associated estradiol is responsible for eNOS stimulation. (a) $\mathrm{HDL}$ was isolated from female C57BL/ 6 mice that had intact ovaries (Intact), had the ovaries removed (OVX), or had the ovaries removed and a $17-\beta$-estradiol pellet implanted $(\mathrm{OVX}+\mathrm{E} 2)$. HDL was also isolated from male age-matched $\mathrm{C} 57 \mathrm{BL} / 6$ mice that had a $17-\beta$-estradiol pellet implanted (Male + E2). In addition, HDL from control male mice was isolated and enriched with $17-\beta$-estradiol in vitro (Male HDL + E2). LDL from female mice (LDL + E2) and BSA (BSA + E2) were also enriched with $17-\beta$-estradiol in vitro. The in vitro-modified HDL, LDL, and BSA were reisolated, and the amount of estradiol associated was quantified before use (see Methods). Human microvascular endothelial cells were pretreated with 0.75 $\mu \mathrm{Ci} / \mathrm{ml}$ of $\left[{ }^{3} \mathrm{H}\right]$ arginine, followed by treatment with $10 \mu \mathrm{g} / \mathrm{ml}$ of each sample or $1 \mu \mathrm{g} / \mathrm{ml}$ of ionomycin for 15 minutes at $37^{\circ} \mathrm{C}$. The cells were then processed to quantify the amount of citrulline generated. Each experiment included controls, using $1 \mathrm{mM} \mathrm{L-NNA}$ to demonstrate that over $99 \%$ of the generated citrulline was due to eNOS activity (data not shown). The data are from eight independent experiments, with triplicate measurements in each experiment (mean $\pm \mathrm{SE}$ ). (b) The same assay as described above was used, with the exception that $10 \mu \mathrm{M}$ of $\mathrm{ICl} 182,780$ was added to each of the reactions. The data are from four independent experiments, with triplicate measurements in each experiment (mean $\pm \mathrm{SE}$ ). 
Table 2

Quantification of double-labeled $\mathrm{HDL}\left({ }^{125} \mathrm{I}\right.$ and $\left[{ }^{3} \mathrm{H}\right]$ estradiol) associated with human microvascular endothelial cells

\begin{tabular}{|c|c|c|c|c|c|c|}
\hline $\begin{array}{l}\text { HDL labeled with }{ }^{125} \\
\text { and }\left[{ }^{3} \mathrm{H}\right] \text { estradiol }\end{array}$ & $0.01 \mu \mathrm{g}$ & $0.05 \mu \mathrm{g}$ & $0.1 \mu \mathrm{g}$ & $0.5 \mu \mathrm{g}$ & $1.0 \mu \mathrm{g}$ & $10.0 \mu \mathrm{g}$ \\
\hline 125I DPMs & $1,103 \pm 213$ & $5,165 \pm 345$ & $9,873 \pm 1,089$ & $33,514 \pm 4,106$ & $57,286 \pm 5,638$ & $83,663 \pm 6,630$ \\
\hline $\begin{array}{l}\text { 125I DPMs plus } \\
\text { blocking SR-BI IgG }\end{array}$ & $20 \pm 6$ & $23 \pm 7$ & $35 \pm 5$ & $59 \pm 18$ & $75 \pm 27$ & $82 \pm 31$ \\
\hline${ }^{3} \mathrm{H}$ DPMs & $326 \pm 213$ & $3,462 \pm 345$ & $64,500 \pm 3,959$ & $512,874 \pm 11,004$ & $517,254 \pm 9,291$ & $526,877 \pm 12,655$ \\
\hline $\begin{array}{l}{ }^{3} \mathrm{H} \text { DPMs plus } \\
\text { blocking SR-BI IgG }\end{array}$ & $12 \pm 6$ & $13 \pm 5$ & $18 \pm 12$ & $22 \pm 16$ & $24 \pm 9$ & $32 \pm 11$ \\
\hline
\end{tabular}

Male HDL was labeled as described in the Methods. The HDL was added to human microvascular endothelial cells for 15 minutes at $37^{\circ} \mathrm{C}$. Where indicated, $50 \mu \mathrm{g} / \mathrm{ml}$ of blocking SR-BI IgG was also added. The cells were washed four times in PBS, and the amount of ${ }^{125}$ and ${ }^{3} \mathrm{H}$ associated with the cells was determined. Each value represents four independent experiments, with triplicate measurements in each experiment (mean \pm SE). DPM, disintegrations per minute.

Female HDL promotes vessel relaxation. The data presented thus far demonstrate that HDL-associated estradiol promotes the stimulation of eNOS in human microvascular endothelial cells in an SR-BI-dependent manner. We next determined if the differential effects of female and male HDL on eNOS activity translated into the ability of these HDLs to stimulate relaxation of the femoral artery. Arteries from C57BL/6 mice were obtained and processed to measure the degree of relaxation (35). The vessels were precontracted with 30 nM 5-hydroxytryptamine and then incubated with various concentrations of HDL isolated from female (Figure $4 \mathrm{a}$, representative trace) and male (Figure 4b, representative trace) mice. Approximately 0.015 pg of estradiol was associated with $1 \mu \mathrm{g}$ of female HDL as determined by a radioimmunoassay (34), whereas estradiol associated with male HDL was not detectable. HDL isolated from female mice caused a dose-dependent relaxation of the vessel with a maximal response at $1 \mu \mathrm{g} / \mathrm{ml}$ of HDL. Acetylcholine (1 $\mu \mathrm{M})$ induced the same extent of relaxation as $1 \mu \mathrm{g} / \mathrm{ml}$ of HDL (data not shown and Figure 5a). In contrast, HDL isolated from males did not promote significant relaxation, even when used at a 10-fold higher concentration than HDL isolated from females (Figure 4b). Figure $4 \mathrm{c}$ is the quantification of vessel relaxation from all of the animals and individual muscle strips. The inclusion of 1 mM L-NNA, an eNOS inhibitor, in the relaxation assay inhibited the ability of acetylcholine or female HDL to induce maximal relaxation (data not shown).

We next used femoral arteries isolated from C57BL/6 mice (wild type) and SR-BI null mice to determine if female $\mathrm{HDL}$ was indeed inducing

\section{Figure 4}

Female HDL but not male HDL potently relaxes arterial contraction. Femoral artery strips from wild-type C57BL/ 6 mice were precontracted with $30 \mathrm{nM} 5$-hydroxytryptamine (5-HT), and cumulative concentrations of HDL, isolated from female (a) or male (b) mice, were added (indicated by arrow). In each single strip, HDL purified from both female and male mice was tested. The order of application of the female HDL versus the male HDL did not affect the results. Note that addition of $1 \mu \mathrm{M}$ acetylcholine (ACh) caused normal relaxation in the same muscle strip in which the HDL purified from male mice did not cause detectable relaxation. (c) Quantification of the extent of relaxation caused by HDL purified from female or male mice. Six muscle strips from three mice were used. vasorelaxation in an SR-BI-dependent manner. Acetylcholine $(1 \mu \mathrm{M})$ induced similar relaxation in arteries isolated from C57BL/6 and SR-BI null mice (Figure 5). In contrast, HDL isolated from female mice did not relax the arteries isolated from SR-BI null mice, although the same HDL preparation induced relaxation in arteries isolated from $\mathrm{C} 57 \mathrm{BL} / 6$ mice (Figure 5a). These data demonstrate that female HDL requires the presence of SR-BI to induce relaxation of isolated femoral arteries. Finally, we denuded the femoral arteries isolated from C57BL/6 mice of endothelial cells to determine if the relaxation was
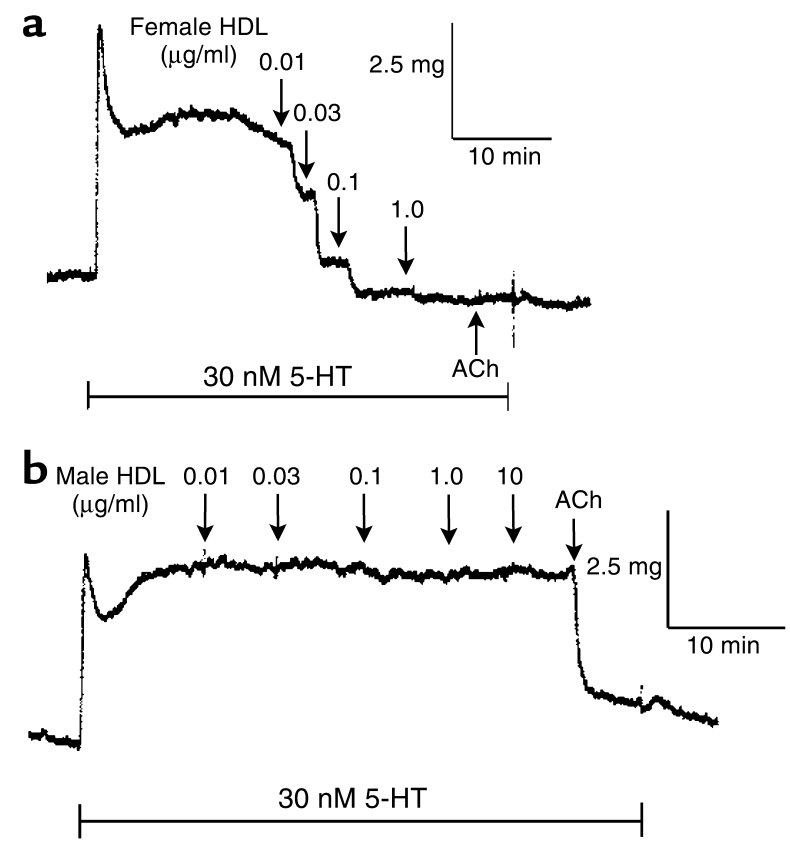

C

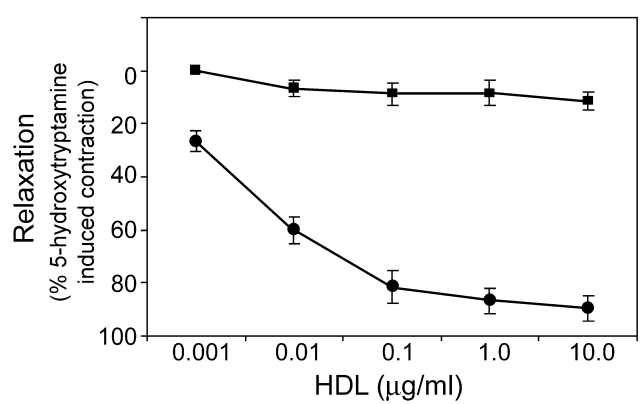



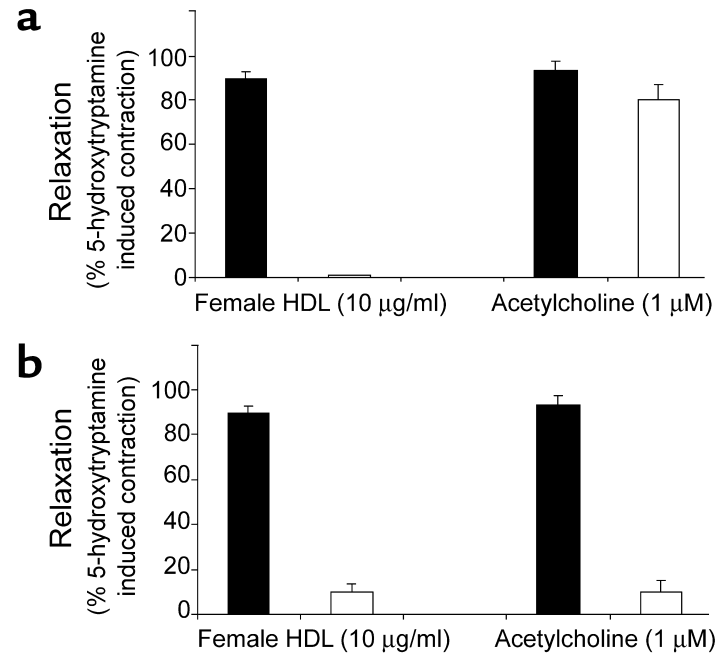

\section{Figure 5}

$\mathrm{HDL}$-induced relaxation is SR-BI and endothelium dependent. (a) Endothelium-intact femoral artery strips isolated from $\mathrm{C} 57 \mathrm{BL} / 6$ or SR-BI null mice were precontracted with $30 \mathrm{nM} 5$-hydroxytryptamine. Acetylcholine $(1 \mu \mathrm{M})$ or $10 \mu \mathrm{g} / \mathrm{ml} \mathrm{HDL}$ purified from female mice was then added to the tissue bath, and the extent of relaxation was measured. Six muscle strips were used for each group. Black bars represent $\mathrm{C} 57 \mathrm{BL} / 6$ mice and white bars SR-BI null mice. (b) Endothelium-intact or endothelium-denuded femoral artery strips isolated from control C57BL/ 6 mice were precontracted with $30 \mathrm{nM}$ 5-hydroxytryptamine. Acetylcholine $(1 \mu \mathrm{M})$ or $10 \mu \mathrm{g} / \mathrm{ml} \mathrm{HDL}$ purified from female mice was then added to the tissue bath, and the extent of relaxation was measured. Three to six muscle strips were used for each group. Black bars represent endothelium intact and white bars endothelium denuded.

endothelium dependent. Both acetylcholine and female HDL induced relaxation on arteries containing an intact endothelium (Figure $5 \mathrm{~b}$ ). In contrast, arteries that did not have an intact endothelium did not respond to acetylcholine or female HDL (Figure $5 \mathrm{~b})$, demonstrating that the relaxation is endothelium dependent. In addition, the inclusion of $1 \mathrm{mM}$ L-NNA, an eNOS inhibitor, in the relaxation assay inhibited the ability of acetylcholine or female HDL to induce maximal relaxation (data not shown).

Estrogen replacement therapy restores the capability of $H D L$ to stimulate eNOS. The above data were generated with HDL isolated from reproductive-competent mice and humans. If our overall hypothesis is correct, then HDL isolated from postmenopausal women should not stimulate eNOS, and HDL isolated from postmenopausal women receiving estrogen replacement therapy should stimulate eNOS. To test this, we isolated HDL from five premenopausal women, five postmenopausal women, and five postmenopausal women receiving estrogen replacement therapy. The HDLs were then used in our HME, live-cell eNOS assay system as described above. The HDL isolated from premenopausal women stimulated eNOS to the same extent as the ionomycin control (Figure 6). In contrast, HDL isolated from postmenopausal women did not substantially stimulate eNOS (Figure 6). Finally, HDL isolated from postmenopausal women receiving estrogen replacement therapy stimulated eNOS, although the variability in the data was greater than that for premenopausal women (Figure 6).

\section{Discussion}

The current data are the first to our knowledge to demonstrate that female HDL but not male HDL isolated from either mice or humans will stimulate eNOS and promote the relaxation of femoral artery strips. Furthermore, we demonstrated that the mechanism of HDL-induced stimulation of eNOS is due to estradiol associated with the lipoprotein. Importantly, the female mouse HDL used in these studies contained only approximately $0.015 \mathrm{pg}$ of estradiol per microgram of $\mathrm{HDL}$, which is a concentration of estradiol that is within physiological plasma levels. These studies illustrate that male and female HDLs are not interchangeable and that future mechanistic studies involving HDL will need to distinguish between male and female HDL. In addition, the data suggest that HDL has a more active role in regulating the cardiovascular system than previously appreciated. The data demonstrate that HDL and the associated estradiol bind to a specific receptor, SR-BI, and generate a signal that stimulates the production of nitric oxide, thereby outlining a novel mechanism that links plasma lipoprotein levels to endothelial function and ultimately to cardiovascular disease.

Yuhanna et al. (4) have demonstrated that HDL will stimulate eNOS; however, significantly higher concentrations of HDL were required than used in the present studies. One possible reason for this difference in the amount of HDL required for eNOS stimulation may be because they used male or a combination of male and female HDL. Our data demonstrate that male HDL can

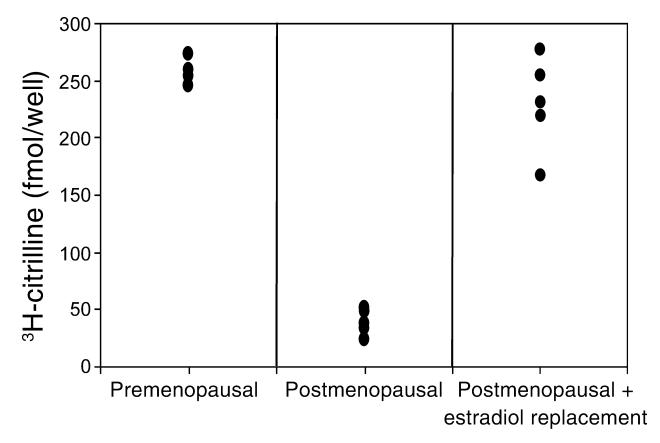

\section{Figure 6}

$\mathrm{HDL}$ isolated from women receiving estrogen replacement therapy stimulates nitric oxide generation. HDL was isolated from five premenopausal women, five postmenopausal women, and five postmenopausal women on estradiol replacement therapy. Human microvascular endothelial cells were pretreated with $0.75 \mu \mathrm{Ci} / \mathrm{ml}$ of $\left[{ }^{3} \mathrm{H}\right]$ arginine and then incubated with $10 \mu \mathrm{g} / \mathrm{ml}$ of the above HDL for 15 minutes. The amount of citrulline generated was then quantified. Each experiment included controls, using $1 \mathrm{mM}$ L-NNA to demonstrate that over $99 \%$ of the generated citrulline was due to eNOS activity (data not shown). The data for each HDL are shown, and each value is the average of six measurements. 
prevent the stimulating effect of female HDL on eNOS, apparently by competing for binding to SR-BI. Importantly, male HDL enriched with estradiol, either in vivo or in vitro, stimulated eNOS, which suggests that male HDL does not have an endogenous inhibitor of eNOS or that some component of female HDL, other than estradiol, is responsible for eNOS stimulation. Another important observation was that only HDL-associated estradiol stimulated eNOS; LDL- and BSA-associated estradiol was unable to stimulate eNOS. This latter point is consistent with our hypothesis that HDL binding to SR-BI targets the delivery of estradiol to eNOS.

Work by Chambliss et al. (7) demonstrated that estrogen receptors are found associated with caveolae and that interaction of estrogen with its receptor resulted in the stimulation of eNOS. Importantly, these studies were done with isolated plasma membranes and isolated caveolae, which precludes the possibility of a transcriptional activation mechanism. Our current data are consistent with a nontranscriptional eNOS activation mechanism, because maximal eNOS stimulation occurs within 1 minute and is rapidly reversed. However, it is unclear how estradiol and estrogen receptor interactions stimulate eNOS. Haynes et al. (29) have demonstrated that estradiol can stimulate akt kinase, which can subsequently phosphorylate and stimulate eNOS; however, it has not been demonstrated that estrogen receptors mediate akt kinase activation. Alternatively, our laboratory has demonstrated that HDL-SR-BI interactions will stimulate eNOS by increasing intracellular ceramide (5). Although it is tempting to speculate that HDL-associated estradiol stimulates ceramide production in an estrogen receptor-dependent manner, this has not been demonstrated. Dissecting the exact mechanism(s) responsible for HDL-associated estradiol to stimulate eNOS will require extensive additional studies and may provide a new paradigm for examining the cardioprotective effects of HDL.

One of the interesting aspects of the current studies is that HDL-associated estradiol stimulates eNOS in an SR-BI-dependent manner at a concentration of HDL that is below the apparent $\mathrm{K}_{\mathrm{d}}$ of HDL binding to SR-BI. However, the data demonstrate that female HDL stimulates eNOS and muscle relaxation in a concentrationand SR-BI-dependent manner. Liu and Krieger (37) recently demonstrated that the $\mathrm{K}_{d}$ for HDL binding to SR-BI was approximately $11 \mu \mathrm{g}$ of protein per milliliter; however, they demonstrated that the "uptake maximum" for cholesteryl ester was only about $106 \mathrm{ng}$ of protein per assay. These data suggest that only a fraction of the SR-BI needs be bound to HDL to achieve the maximum uptake of cholesteryl ester. Our data are consistent with these findings. In addition, we $(5,21$, 38 ) and others (4) have demonstrated that SR-BI is highly enriched in caveolae in endothelial cells, and it is possible that HDL-SR-BI interactions in caveolae may differ from receptors not associated with caveolae. For instance, caveolae can invaginate or vesiculate (39), which would have the net result of decreasing the volume associated with the HDL-SR-BI interaction. This putative mechanism would thereby increase the effective local concentration of HDL and may well bring it close to the apparent $K_{d}$. SR-BI, estrogen receptors, and eNOS are all localized to endothelial caveolae (40), which potentially generates a unique environment to directly deliver and concentrate the effects of estradiol on eNOS. We do not know how estradiol stimulates eNOS. The data suggest that an estrogen receptor is involved, but it is unclear if the $\alpha$, the $\beta$, or the recently identified truncated receptor is involved. Furthermore, we were unable to measure the effective local concentration of estradiol associated with the putative caveolae-signaling complex; however, it is presumably higher locally than would be expected if the estradiol was randomly distributed throughout the cells. Finally, the available data concerning estradiol stimulation of eNOS suggest that it occurs through a signal transduction mechanism that amplifies the initial input, which further suggests that all of the SR-BI and/or estrogen receptors need not be occupied to stimulate eNOS activity and muscle relaxation. Future studies will focus on the detailed molecular mechanisms that allow low concentrations of HDL and estradiol to stimulate eNOS.

Many studies have demonstrated that high plasma HDL levels correlate with a decreased risk of cardiovascular disease (14-16) and that women, before menopause, are afforded more protection than men (22-24). Our data suggest that one mechanism which may contribute to the cardioprotection seen in premenopausal women is the delivery of HDL-associated estradiol directly to caveola-localized eNOS through SR-BI. A critical test of this hypothesis was done using HDL isolated from premenopausal women, postmenopausal women, and postmenopausal women receiving estrogen replacement therapy. In contrast to HDL isolated from premenopausal women, HDL isolated from postmenopausal women did not stimulate eNOS. The levels of estradiol in serum from the postmenopausal women were at the limit of detection and comparable to that of men (data not shown). This inability of HDL isolated from postmenopausal women to stimulate eNOS correlates with the increase in the risk of developing cardiovascular disease. However, HDL isolated from postmenopausal women receiving estrogen replacement therapy was able to stimulate eNOS, although to differing extents.

The current data are especially interesting because the HERS trial (41) documented that estrogen replacement therapy was not beneficial in preventing cardiovascular events in women with advanced atherosclerosis. Although the data demonstrate that replacement of estradiol in women with established atherosclerosis did not promote the regression of the lesions, it is unclear what estradiol may be doing in women before the establishment of lesions. The initiation of atherosclerotic lesion formation is complicated and involves 
multiple mechanisms, several of which can be influenced by nitric oxide. The current study demonstrates that in both humans and mice, estradiol replacement will allow HDL to associate with estradiol and that this HDL is able to stimulate eNOS. The mechanistic role of how estradiol may function in preventing the initiation and progression of atherosclerosis has not been extensively studied. In summary, our data provide a mechanistic outline of how HDL and estradiol may function together to decrease the initiation and progression of atherosclerosis.

\section{Acknowledgments}

We thank William V. Everson for critically reading the manuscript and providing intellectual input and the Cardiovascular Research Group for invaluable advice and assistance. This work was supported, in part, by a COBRE grant (P20 RR15592) from the National Center for Research Resources at NIH and by grants from the National Heart, Lung, and Blood Institute (HL62844 and HL64056 to E.J. Smart and HL67284 to M. Gong).

1. Mendelsohn, M.E. 2002. Protective effects of estrogen on the cardiovascular system. Am. J. Cardiol. 89:12E-17E.

2. Mendelsohn, M.E. 2000. Mechanisms of estrogen action in the cardiovascular system. J. Steroid Biochem. 74:337-343.

3. von Eckardstein, A., and Assmann, G. 2000. Prevention of coronary heart disease by raising high-density lipoprotein cholesterol. Curr. Opin. Lipidol. 11:627-637.

4. Yuhanna, I.S., et al. 2001. High-density lipoprotein binding to scavenger receptor-BI activates endothelial nitric oxide synthase. Nat. Med. 7:853-857.

5. Li, X.-A., et al. 2002. High-density lipoprotein binding to scavenger receptor class $B$, type I activates endothelial nitric oxide synthase in a ceramide-dependent manner. J. Biol. Chem. 277:11058-11063.

6. Hisamoto, K., et al. 2001. Estrogen induces the akt-dependent activation of endothelial nitric-oxide synthase in vascular endothelial cells. J. Biol. Chem. 276:3459-3467.

7. Chambliss, K.L., et al. 2000. Estrogen receptor alpha and endothelial nitric oxide synthase are organized into a function signaling module in caveolae. Circ. Res. 87:E44-E52.

8. Chambliss, K.L., Yuhanna, I.S., Anderson, R.G., Mendelsohn, M.E., and Shaul, P.W. 2002. ER $\beta$ has nongenomic action in caveolae. Mol. Endocrinol. 16:938-946.

9. Rubbo, H., Trostchansky, A., Botti, H., and Batthyany, C. 2002. Interactions of nitric oxide and peroxynitrite with low-density lipoprotein. Biol. Chem. 383:547-552.

10. Laroux, F.S., et al. 2000. Role of nitric oxide in the regulation of acute and chronic inflammation. Antioxid. Redox Signal. 2:391-396.

11. Lefer, A.M. 1997. Nitric oxide: nature's naturally occurring leukocyte inhibitor. Circulation. 95:553-554.

12. Li, H., and Forstermann, U. 2000. Nitric oxide in the pathogenesis of vascular disease. J. Pathol. 190:244-254.

13. Taddei, S., Virdis, A., Ghiadoni, L., Salvetti, G., and Salvetti, A. 2000. Endothelial dysfunction in hypertension. J. Nephrol. 13:205-210.

14. O'Connell, B.J., and Genest, J. 2001. High-density lipoproteins and endothelial function. Circulation. 16:1978-1983.

15. Libby, P. 2001. Managing the risk of atherosclerosis: the role of high-density lipoprotein. Am. J. Cardiol. 20:3N-8N.

16. Tonkin, A. 2001. High-density lipoprotein cholesterol and treatment guidelines. Am. J. Cardiol. 20:41N-44N.

17. Bruce, C., Chouinard, R.A., and Tall, A.R. 1998. Plasma lipid transfer proteins, high-density lipoproteins, and reverse cholesterol transport. Annu. Rev. Nutr. 18:297-330.
18. Sviridov, D., and Nestel, P. 2002. Dynamics of reverse cholesterol transport: protection against atherosclerosis. Atherosclerosis. 161:245-254.

19. Trigatti, B., Rigotti, A., and Krieger, M. 2000. The role of the high-density lipoprotein receptor SR-BI in cholesterol metabolism. Curr. Opin. Lipidol. 11:123-131.

20. Krieger, M. 2001. Scavenger receptor class B type I is a multiligand HDL receptor that influences diverse physiologic systems. J. Clin. Invest. 108:793-797. doi:10.1172/JCI200114011.

21. Uittenbogaard, A., Shaul, P.W., Yuhanna, I.S., Blair, A., and Smart, E.J. 2000. High density lipoprotein prevents oxidized low density lipoprotein-induced inhibition of endothelial nitric-oxide synthase localization and activation in caveolae. J. Biol. Chem. 275:11278-11283.

22. Matthews, K.A., Kuller, L.H., Sutton-Tyrrell, K., and Chang, Y.F. 2001. Changes in cardiovascular risk factors during the perimenopause and postmenopause and carotid artery atherosclerosis in healthy women. Stroke. 32:1104-1111.

23. Cid, M.C., Schnaper, H.W., and Kleinman, H.K. 2002. Estrogens and the vascular endothelium. Ann. N. Y. Acad. Sci. 966:143-157.

24. Langer, R.D. 2002. Hormone replacement and the prevention of cardiovascular disease. Am. J. Cardiol. 89:36E-46E.

25. Tolbert, T., and Oparil, S. 2001. Cardiovascular effects of estrogen. Am. J. Hypertens. 14:186S-193S.

26. Sader, M.A., and Celermajer, D.S. 2002. Endothelial function, vascular reactivity and gender differences in the cardiovascular system. Cardiovasc. Res. 53:597-604.

27. Chambliss, K.L., and Shaul, P.W. 2002. Rapid activation of endothelial NO synthase by estrogen: evidence for a steroid receptor fast-action complex (SRFC) in caveolae. Steroids. 67:413-419.

28. Wyckoff, M.H., et al. 2001. Plasma membrane estrogen receptors are cou-

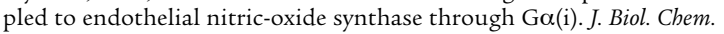
276:27071-27076.

29. Haynes, M.P., et al. 2000. Membrane estrogen receptor engagement activates endothelial nitric oxide synthase via the PI3-kinase-Akt pathway in human endothelial cells. Circ. Res. 87:677-682.

30. Davda, R.K., Chandler, L.J., Crews, F.T., and Guzman, N.J. 1993. Ethanol enhances the endothelial nitric oxide synthase response to agonists. Hypertension. 21:939-943.

31. Schumaker, V.N., and Puppione, D.L. 1986. Sequential flotation ultracentrifugation. In Plasma lipoproteins. Part A: preparation, structure, and molecular biology. J.P. Segrest and J.J. Albers, editors. Academic Press, Inc. Orlando, Florida, USA. 155-170.

32. Gwynne, J.T., and Mahaffee, D.D. 1989. Rat adrenal uptake and metabolism of high density lipoprotein cholesteryl ester. J. Biol. Chem. 264:8141-8150.

33. Bilheimer, D.W., Eisenberg, S., and Levy, R.I. 1972. The metabolism of very low density lipoprotein. Biochim. Biophys. Acta. 260:212-221.

34. Dubal, D.B., et al. 2001. Estrogen receptor $\alpha$, not $\beta$, is a critical link in estradiol-mediated protection against brain injury. Proc. Natl. Acad. Sci. U. S. A. 98:1952-1957.

35. Gong, M.C., et al. 1992. Myosin light chain phosphatase activities and the effects of phosphatase inhibitors in tonic and phasic smooth muscle. J. Biol. Chem. 267:14662-14668.

36. Simoncini, T., et al. 2002. Genomic and nongenomic mechanisms of nitric oxide synthase induction in human endothelial cells by a fourthgeneration selective estrogen receptor modulator. Endocrinology. 143:2052-2061.

37. Liu, B., and Krieger, M. 2002. Highly purified scavenger receptor class B, type I reconstituted into phosphatidylcholine/cholesterol liposomes mediates high affinity high density lipoprotein binding and selective lipid uptake. J. Biol. Chem. 277:34125-34135.

38. Kincer, J.F., et al. 2002. Hypercholesterolemia promotes a CD36-dependent and endothelial nitric oxide synthase-mediated vascular dysfunction. J. Biol. Chem. 277:23525-23533.

39. Smart, E.J., et al. 1999. Caveolins, liquid-ordered domains, and signal transduction. Mol. Cell. Biol. 19:7289-7304.

40. Shaul, P.W. 2002. Regulation of endothelial nitric oxide synthase: location, location, location. Annu. Rev. Physiol. 64:749-774.

41. Grady, D., et al. 2002. Cardiovascular disease outcomes during 6.8 years of hormone therapy: heart and estrogen/progestin replacement study follow-up (HERS II). JAMA. 288:49-57. 